\title{
Sexual Function
}

National Cancer Institute

\section{Source}

National Cancer Institute. Sexual Function. NCI Thesaurus. Code C118256.

The bodily processes that include arousal, erection, orgasm, and ejaculation. 